\title{
Prinses Diana als postmoderne heilige en een kerkdienst in een museum: Tendensen in de dynamiek van cultus en cultuur vanuit een West-Europees perspectief
}

\author{
M Barnard*
}

(Universiteit van Pretoria)

\section{ABSTRACT}

Princess Diana as a post-modern saint and a church service in a museum: Tendencies in the dynamics of liturgy and culture from a western European perspective

The publication of a new service book of the reformed and Lutheran churches in the Netherlands, and of a new liturgical handbook, have given the science of liturgy in that country a new impulse. The development of the discipline is focused on a cultural-anthropological perspective as well as on a reflection of the discipline in itself. In this article, two illustrating examples of four dimensions in this dynamism are given. The four dimensions are then discussed. These four dimensions are: 1 . the popularity of rituals and symbols; 2. the interference of different systems of meaning; 3. the restoration of the two domains of art and liturgy into the one domain of imagination; and 4. the (sometimes radical) recontextualisation of liturgy. These dimensions of liturgy are all tendencies in the dynamism of cult and culture, and to understand them, it is necessary to use cultural-anthropological methods in the science of liturgy.

\section{INLEIDING}

In Europa is de liturgiewetenschap of liturgiek sterk in beweging. Het verschijnen in Nederland in 1998 van De weg van de liturgie: Tradities, achtergronden, praktijk (Oskamp en Schuman 1998) en enkele maanden later van Dienstboek - een proeve: Schrift, maaltijd, gebed (Dienstboek 1998) heeft de liturgiek aan protestantse zijde daar een nieuwe impuls gegeven. De liturgie werd opnieuw onderwerp van gesprek en van reflectie. In de liturgiewetenschap heeft dat geleid tot een concentratie

\footnotetext{
${ }^{1}$ Dit artikel is een bewerking van een lezing die de auteur op 14 maart 2001 heeft gehouden op de constituerende vergadering van de "Navorsingseenheid: homiletiek, liturgiek en himnologie" van het Departement Praktiese Teologie van de Fakulteit Teologie van de Universiteit van Pretoria, onder leiding van de dekaan, prof dr C J A Vos.

" Lid van HOMLIT, Departement Praktiese Teologie, Universiteit van Pretoria.
} 
op het cultureel-antropologische perspectief van de vakbeoefening en tot een reflectie op het statuut en de methodiek van het vak. Meer dan ooit kregen deze concentratie en reflectie in oecumenische samenwerkingen gestalte. In dit artikel proberen we een synthese van de ontwikkelingen in de afgelopen jaren te geven door in te gaan op de dynamiek van cultus en cultuur en enkele tendensen daarvan te schetsen. Tegelijkertijd laten we zien welke implicaties de aandacht voor deze dynamiek heeft voor de liturgiek als vak. Daarbij verwijzen we steeds naar fundamentelere en meer diepgravende studies, nationaal en internationaal.

Internationaal verschenen op het gebied van de zogenaamde ritual studies twee theoretische handboeken van vooraanstaande cultureelantropologen, Bell (1997) en Rappaport (1999). Ook de bekende ritenexpert Ronald Grimes publiceerde een nieuw werk (Grimes 2000). Hier moet zeker ook de gedurfde liturgiegeschiedenis van Bernhard Lang worden genoemd (Lang 1998). Voor Nederland is het boek van de Zuid Afrikanen Vos en Pieterse belangrijk, dat de liturgiek als handelingswetenschap opvat (Vos en Pieterse 1997). In Nederland publiceerde Lukken een belangrijk werk, Rituelen in overvloed, waarin de auteur decennia van ritenonderzoek samenvat (Lukken 1999). Een inleiding tot de antropologische grondslagen van christelijke ritualiteit biedt Ritueel bestek (Barnard en Post 2001). Post voerde verkenningen uit van populair religieus ritueel in Het wonder van Dokkum (Post 2000b). Een reflectie op het vak liturgiek is te vinden in Liturgiek als wetenschap van christelijke riten en symbolen (Barnard 2000). Voor overige publicaties verwijzen we naar de laatste jaargangen van het Jaarboek voor liturgieonderzoek en naar de literatuurberichten die geregeld verschenen zijn in Praktische Theologie. Wereldwijd houden zowel de gereformeerde kerken als de lutherse zich intensief bezig met de verhouding tussen liturgie en cultuur. De Lutheran World Federation ( $L W F$ ) publiceerde drie rapporten over de thematiek (Stauffer 1994, 1996 en 1998). De World Alliance of Reformed Churches (WARC) organiseerde in januari 2001 een consultatie over de 'History and renewal of worship in Reformed churches'; er is binnen afzienbare tijd een publicatie van te verwachten, waarin wereldwijd de ontwikkelingen in de reformatorische liturgie worden geschetst (Visscher 2002). Vanuit Zuid Afrika nam dr Coenie Burger (Stellenbosch) aan de consultatie deel namens de NGK, vanuit Nederland de auteur van dit artikel namens de Samen op Weg-kerken (hervormd, gereformeerd, luthers).

Dit artikel zet in met twee voorbeelden, die illustratief zijn voor vier tendensen in de dynamiek van cultus en cultuur (1). Na deze voorbeelden worden die vier tendensen achtereenvolgens uitgewerkt en telkens gerelateerd aan de liturgiewetenschap: hoe kan deze tendens het beste worden onderzocht; met andere woorden, welke implicaties hebben de gesignaleerde tendensen voor het statuut van de liturgiek? De vier 
tendensen zijn: een bloei aan rituelen en symbolen (2), een interferentie van verschillende betekenissystemen (3), het herstel van het oorspronkelijk ene domein van de verbeelding, dat evalueerde tot de twee domeinen van kunst en liturgie (4), en recontextualisering van de liturgie (5).

Vooraf maken we nog een opmerking over in dit artikel gebruikte terminologie. Over de termen cultus en cultuur in de titel van dit artikel komen we nog te spreken. Nu merken we al vast op, dat cultus hier doelt op de liturgie opgevat als een symbolische orde. De termen liturgiewetenschap en liturgiek gebruiken we door elkaar heen. Soms wordt een onderscheid tussen beide noties gemaakt, maar in de regel is dat gekunsteld en onnodig, zeker als de gehanteerde methodiek vooral cultureelantropologisch is.

\section{TWEE VOORBEELDEN: DIANA ALS POSTMODERNE HEILIGE EN EEN KERKDIENST IN EEN MUSEUM}

\subsection{Prinses Diana als postmoderne heilige}

Op een tentoonstelling Heaven, waar de relatie tussen religie en populaire cultuur werd onderzocht, stond een beeld van een vrouwelijke heilige, de handen gevouwen, gehuld in een rijkelijk geplooid gewaad. Een klassiek heiligenbeeld, - behalve de kop: dat was overduidelijk het hoofd van Prinses Diana (Barnard 2001:56). Het beeld werd gesneden door het Italiaanse kerkbeeldenbedrijf Demetz. Het speelt overduidelijk met hoe mensen zich de dood van de prinses toeeigenden. De prinses werd na haar dood - zo zegt het beeld als het ware - vereerd als een postmoderne heilige (vgl. Post 2000a). Bij de hekken van Kensington Palace, de woning van de prinses, werden bergen bloemen gelegd, langs de route van de rouwstoet stonden honderdenduizenden mensen, er werd publiekelijk gerouwd. Uit liturgisch oogpunt was niet alleen deze spontane, min of meer religieuze, rituele uitbarsting interessant, maar ook de uitvaartdienst. Deze liturgie was een mixture van de liturgie van de Church of England, een popsong van Elton John (nota bene, oorspronkelijk geschreven voor het sekssymbool Marilyn Monroe!) en een toespraak van een broer van de overledene; verschillende betekenissystemen christelijke liturgie, popmuziek en familie - werden vermengd tot een nieuw systeem. Daarmee werd een liturgische praktijk die bij vele begrafenissen en ook huwelijken voorkomt, op een bepaalde manier geijkt.

Het voorbeeld is illustratief voor twee tendensen in de dynamiek van cultus en cultuur:

1 een bloei aan rituelen en symbolen in de westerse cultuur;

2 een interferentie van verschillende betekenissystemen binnen dit rituele veld. 


\subsection{Een kerkdienst in een museum}

Een tweede voorbeeld betreft een kerkdienst in het bekende Rotterdamse museum Boymans van Beuningen, op tweede Paasdag 1998, waarin ik zelf voorganger was. De dienst is beschreven en veel besproken in wetenschappelijke en vakliteratuur en ook in de pers (Barnard en Post 2001:56-62; vgl. Grond 1998:32; Post 1998:49; Lukken 1999:211; Augustus-Kersten 2000; Blankesteijn 2001). In het museum was een tentoonstelling, "Verzachtende omstandigheden" (Museum Boijmans 1998). Bekende kunstenaars - Rob Birza, Jan Dibbets, Marlene Dumas (oorspronkelijk uit Zuid Afrika afkomstig), Henri Jacobs, Luc Tuymans, Willem Oorebeek, Giulio Paolini, Jeff Wall en Ludger Gerdes - kregen en aanvaardden de opdracht om een ontwerp voor een wollen wandtapijt te maken, dat in het nieuwe Paleis van Justitie in Den Bosch, in het zuiden van Nederland, zou komen te hangen. Wollen tapijten, "verzachtende omstandigheden", zouden de context vormen van de rechtspraak: de zittingzaal slaat de verdachte niet om de oren met zijn misstap, maar wijst op wat hem in enigerlei mate verontschuldigt. De 36 enorme wollen tapijten, totaal 600 meter, waren gemaakt in Desso's tapijtfabriek. Ze hadden alle op één of andere manier de rechtsgang tot thema: recht en onrecht, de verborgenheid en ontdekking van de waarheid, de twijfel en overtuiging van de rechter en bovenal de verzachtende omstandigheden voor de verdachte. Dat dit thema's zijn die ook in het geloof een voorname rol spelen, zal duidelijk zijn.

De tapijten hingen in de grote zaal op de eerste verdieping van het museum. Voor de viering waren 300 stoelen neergezet tussen de tapijten van Marlene Dumas en Luc Tuymans. Een vocaal kwartet en de gemeentezang werden begeleid door een harpiste. Bijna 300 mensen kwamen op een regenachtige tweede Paasdag naar het museum. De dienst vond vóór de openingstijd van het museum plaats. De liturgie die werd gevolgd had de structuur van een getijdendienst. Op de plek van het "psalmen-gebed" stond een compilatie van meditatieve gedachten bij de tapijten en van schriftteksten uit (vooral) de Psalmen en het evangelie. In de meditatie viel het accent meer op de schriftuitleg. Het Luthers lectionarium werd gevolgd, dat voor de tweede Paasdag Psalm 139 als introïtus aanwijst: "Heer die mij ziet zoals ik ben,/ dieper dan ik mijzelf ooit ken./ kent Gij mij..." Als lezing geeft het lectionarium Handelingen 10:34-43 aan: "Nu weet ik zeker dat God geen aanzien des persoons kent..." en "Hij (de Opgestane) is door God aangesteld tot rechter over levenden en doden".

Dit voorbeeld is illustratief voor twee andere, onderling samenhangende, tendensen in de dynamiek van cultus en cultuur, overigens verwant met de twee eerder genoemde: 
3 het oorspronkelijk ene domein van de verbeelding, dat evolueerde tot de twee domeinen van kunst en geloof (of: cultuur en cultus, of cultuur en liturgie) wordt weer hersteld;

4 een (soms radicale) recontextualisering van de liturgie.

In het vervolg van dit artikel ga ik op elk van de vier gesignaleerde en onderling nauw samenhangende tendensen nader in. We relateren die tendensen telkens aan het statuut van de liturgiewetenschap als discipline. De methodiek van een wetenschap wordt immers bepaald door het te onderzoeken object. Waar het object aan verandering onderhevig is en de relatie tussen cultus en cultuur is een dynamische - zal ook het statuut van die wetenschappelijke discipline zich telkens moeten aanpassen.

\section{EERSTE TENDENS: EEN BLOEI AAN RITUELEN EN SYMBOLEN}

\subsection{Een bloei aan rituelen en symbolen}

In de Nederlandse samenleving is een bloei aan rituelen waar te nemen (Barnard 2000:10-12; Lukken 1999). Op "Koninginnedag", 30 april, gaan Nederlanders massaal de straat op voor "vrijmarkten", spelen en vermaak, en kleurt het hele land oranje door de wimpels aan de roodwit-blauwe vlag, door de kleding die mensen dragen en door ander gebruik van die kleur (het koningshuis is het huis van Oranje). De herdenking van doden uit de Tweede Wereldoorlog op 4 mei en van de Bevrijding op 5 mei (Barnard 2001:187-193) trekken vele belangstellenden. Duizenden mensen nemen telkens deel aan "stille tochten" die georganiseerd worden na een ramp of nadat iemand is vermoord: zij leggen bloemen op de plek van de ramp, dragen fakkels, luisteren naar toespraken van de burgemeester en familieleden van de slachtoffers, horen naar de declamatie van gedichten etcetera. Er zijn party's als een kind geboren is en uitgebreide huwelijks- en begrafenisrituelen. Studentenverenigingen en hun specifieke mores zijn populair onder studenten. Daarnaast en in het algemeen zijn er talloze feesten die wij te vieren hebben in wat wel genoemd is een "feestcultuur": de West-Europese cultuur van overvloed en rijkdom.

Voor een buitenstaander is de situatie met betrekking tot de ritualiteit in Zuid Afrika moeilijk te beoordelen zonder nader onderzoek; enkele globale opmerkingen moeten volstaan. Het land lijkt op een tweesprong te staan, waarbij de ene weg naar een panamerikanisering leidt en de andere naar een Afrika Renaissance; niet uitgesloten is dat een deel van de bevolking op deze splitsing linksaf slaat en een ander deel rechtsaf. Met name de richting van de Afrika Renaissance zou ook een her- 
nieuwde aandacht voor het ritueel-symbolische moment in de Afrikaanse culturen kunnen impliceren, als deze renaissance tenminste niet alleen een economische zal zijn (De Klerk 2002). Overigens ligt aan het nieuwe Zuid Afrika een belangrijk ritueel ten grondslag: het indrukwekkende verslag dat Antjie Krog schreef over het werk van de Waarheids- en Verzoeningscommissie in Zuid Afrika laat zich lezen als de beschrijving van een - uiterst pijnlijk - verzoeningsritueel (Krog 1998/1999:142v.).

Deze aandacht voor ritualiteit en symboliek is te kwalificeren als een nieuw cultureel bewustzijn. Cultuur is een gecompliceerd en veelomvattend begrip (Barnard 2001a). Vele omschrijvingen ervan wijzen in de richting van betekenis en symbool. Cultuur laat zich kortweg omschrijven als een "geordend systeem van betekenis en symbolen" (Geertz 1993 (1973):144), of als een "symbolische orde" (Lukken 1997:136). Anders gezegd, in de cultuur gaat het vooral om de productie van betekenis, van zingeving die aan esthetische, sociologische, economische, religieuze en antropologische tendensen of facta wordt toegekend.

Ik ga nader in op het begrip "cultuur" aan de hand van een Nederlands onderzoeksproject dat exemplarisch is voor het hedendaagse denken over cultuur. Vervolgens sta ik kort stil bij de begrippen "symbool" en "ritueel". We sluiten ons aan bij de tendens om deze noties niet in strakke definities te (pogen te) vatten, maar laten enkele dimensies en perspectieven ervan zien. Definities laten zich immers gemakkelijk door andere vervangen, waarbij doorgaans dezelfde dimensies een rol spelen als in de eerdere maar in een andere verhouding.

\subsection{Cultuur}

In vijf luxe uitgegeven delen verschijnt momenteel een reeks Nederlandse cultuur in Europese context, waarbij in de eerste vier delen vier jaren - 1650,1800, 1900 en 1950 - als ijkpunt worden genomen en het vijfde deel een terugblik biedt op het gehele project (Frijhoff en Spies 1999; Bank en Van Buuren 2000; Schuyt en Taverne 2000; Kloek en Mijnhardt 2001; Fokkema en Gijzenhout z.j.). De banden vormen een synthese van onderzoek naar de Nederlandse cultuur in de genoemde context; aan ieder deel liggen afzonderlijke deelpublicaties ten grondslag. De boeken zijn ook te beschouwen als state of the art van de beoefening van de actuele cultuurgeschiedenis. Daarom zijn ze van belang voor de moderne liturgiewetenschap, die zich immers in toenemende mate bezig houdt met het onderzoek naar de dynamische relatie tussen cultus en cultuur: inculturatie en contextualisatie zijn kernwoorden in de hedendaagse vakbeoefening. Het is significant dat een liturgiewetenschapper, P G J Post, deel uitmaakt van de stuurgroep die het project begeleidt: de antropologische en culturele dimensie maakt deel uit van het liturgiewetenschappelijke onderzoek, maar omgekeerd participeert liturgiewetenschappelijke research ook aan de culturele wetenschap. Deze concentratie op de 
cultureel-antropologische dimensie van de liturgiek weerspiegelt wereldwijde ontwikkelingen in de liturgie, zowel aan katholieke als aan protestantse zijde (Stauffer 1994; 1996; 1997; 1998; Vischer 2002). De auteurs van het eerste deel van Nederlandse cultuur..., Willem Frijhoff en Marijke Spies, staan nadrukkelijk stil bij wat cultuur is (Frijhoff en Spies 1999:52-55). Minder dan dat zij cultuur vastleggen in definities bepalen zij enkele perspectieven en dimensies ervan.

Hoewel Frijhoff en Spies cultuur als resultante van een productieproces beschouwen, vinden zij het specifieke ervan toch in "dat ze betekenis schept" (Frijhoff en Spies 1999:52). Cultuur is dus niet alleen een product, maar ook een producent, namelijk van betekenis. $\mathrm{Zij}$ wordt niet alleen gecreëerd, maar kent ook zelf een scheppende dynamiek. $\mathrm{Zij}$ wordt niet alleen geproduceerd, maar is zelf ook een producerende factor met een eigen dynamiek (Frijhoff en Spies 1999:53). Cultureel handelen laat zich dan omschrijven als het "zinvolle verbanden tussen verspreide en op het oog onsamenhangende elementen van de werkelijkheid leggen, tussen dingen, mensen, beelden, handelingen" (Frijhoff en Spies 1999:53). Dingen en handelingen krijgen dus een betekenis boven hun nuttigheidswaarde uit, en deze betekenissen zijn meervoudig.

\subsection{Symbool en ritueel}

Na deze nadere bepaling van het begrip "cultuur", staan we vervolgens stil bij het symboolbegrip (Post 2001:34v.; Lukken 1998:18-44). Ik illustreer de verschillende dimensies van "symbool" telkens aan de hand van "licht", dat in de symboliek nauw verbonden is met zon, vuur, kleur etcetera (Barnard 2001c).

De etymologische oorsprong van het woord symbool is het Griekse $\sigma v \mu \beta \alpha ́ \lambda \lambda \omega$ : bij elkaar brengen. In een religieuze context betekent dat: het bij elkaar brengen van het menselijke en het goddelijke domein. Het werkwoord komt voor in het kerstevangelie. Lukas 2:19: "Maria bewaarde al deze woorden, die overwegende ( $\sigma \nu \mu \beta \alpha ́ \lambda \lambda o v \sigma \alpha)$ in haar hart". Het laat zich vermoeden dat zij nogal confuus was van alles wat er gebeurd was (de geboorte, de herders en de engelen) en dan probeert zij de dingen - of beter nog: het hemelse en het aardse domein - samen te brengen, zij symboliseert (Post 2001:34).

Een symbool is open voor verschillende betekenissen en daarom tegengesteld aan een wetenschappelijke term. In de wetenschap is "licht" vast te stellen als een elektromagnetische straling met een golflengte van ongeveer 400 tot 780 millimicron. In de symboliek, bijvoorbeeld in de liturgie, is het een ambivalent begrip. Het duidt er (bijvoorbeeld) de godheid aan, zowel in haar helende als in haar vernietigende kracht (Johannes 1:9 en 3:19!). Kaarsen of fakkels kunnen zowel teken van hoop en 
verbondenheid, als ook van afweer en bezwering van het kwade zijn. Vuur geeft warmte, maar verteert ook.

Een volgende dimensie van symbool is dat het participatie vereist. Licht blijft ook in de kerk een bepaalde elektromagnetische straling, tenzij ik participeer aan het verhaal dat spreekt van God die "woont in een ontoegankelijk licht" (1 Timoteüs 6:16), en van Christus als "Zon der gerechtigheid", die komt om het kaf van het koren te scheiden en die het kaf zal "verbranden met onuitblusbaar vuur", maar die ook zal "dopen met de heilige Geest en met vuur" (Matteüs 3: 7-12 par.) Dat verhaal noemt ook mijzelf verlicht (Efeze 5:8). Deze tendens maakt duidelijk, dat het symbool niet ontologisch met God verbonden is. Anders gezegd, God wordt in het symbool niet geobjectiveerd. Het symbool is eerder een, wat Jan-Luc Marion heeft genoemd: icoon, "een doorgeefluik van de Godontmoeting", waarin de mens zijn transcendentie ervaart en over de grenzen van het bepaalde heen, interpreteert, overdenkt, mediteert en God zoekt en ontmoet (kort en helder over Marion: Houtepen 2001:158172).

Het symbool brengt vervolgens verschillende domeinen bijeen, omdat er een equivalentie tussen beide is tot in het symbool zelf. Licht en vuur kunnen verwijzen naar verlichting en helderheid, naar warmte en hoop, en ook naar purificatie en oordeel omdat zij in zichzelf, dus als licht en vuur, warmte en licht geven, en ook branden (Post 2001:35). Doopwater is symbool voor de reiniging van de zonden omdat het ook afwaswater is, dus in zichzelf een reinigend effect heeft.

Een dimensie van het symbool die enigszins in tegenspraak is met de vorige: symbolen berusten ook op conventies en codes; er is een symbolische canon. Als ik rood-wit-blauw zie, denk ik aan de Nederlandse vlag en dus aan Nederland. Toch hebben die kleuren en hun combinatie op zichzelf niets met Nederland te maken. De conventie of code bepaalt dat deze kleurencombinatie tot symbool van Nederland is geworden. De verandering van de Zuid Afrikaanse vlag een aantal jaren geleden, is een symbool van het nieuwe Zuid Afrika van de postapartheid periode.

Tenslotte: symbolen kunnen elementen uit de werkelijkheid zijn. Zij zijn nauw verwant aan symboolhandelingen en aan symbooltaal. Bij een symbolische analyse van gesproken of geschreven woorden spelen de stem van de spreker, de gebaren die erbij worden gemaakt, de bladspiegel, de drukletter die is gebruikt en andere elementen, een rol. Wanneer we over woorden-op-zichzelf als symbolen spreken, gebruiken we de aanduiding "metafoor".

Van hieruit is het nu niet moeilijk om het ritueel nader te omschrijven. Een ritueel is een complex van symbooltaal, symboolhandelingen en symbolen (Lukken 1999). Anders gezegd, een ritueel is een symbolische orde. 


\subsection{Liturgie als systeem van riten en symbolen}

Kerken in een geseculariseerde cultuur hebben de neiging zich in zichzelf terug te trekken en te verkerkelijken. De liturgiek kan als wetenschap een kritische functie ten opzichte van deze tendens vervullen door een methodiek te kiezen die de continuïteit en discontinuïteit tussen de eredienst en de cultuur blootlegt en die laat zien hoe mensen aan liturgie participeren en zich die toe-eigenen. Deze methode wordt gevonden in wat wel genoemd wordt de ritual studies, in feite een platform waaraan vele disciplines deelnemen: culturele antropologie, culturele geschiedenis en andere culturele studies, theologie, sociologie, psychologie, etcetera. De keuze van deze methodiek impliceert dat we naar liturgie leren kijken als naar een symbolische orde, of als naar een systeem van riten en symbolen. Nog anders gezegd, als naar een cultus die in een dynamische relatie tot de cultuur staat (Lukken 1999; Barnard 2000; Barnard en Post 2001). Het woord cultus voor liturgie is in dit verband zinvol, omdat het dezelfde stam heeft als cultuur en zo onmiddellijk de samenhang daarmee duidelijk maakt. Wij gebruiken "cultus" dus voor liturgie, opgevat als symbolische orde. Het betekent ook dat de liturgiewetenschap zich nadrukkelijk met andere disciplines bezighoudt, bijvoorbeeld de culturele antropologie (Bell 1997; Rappaport 1999).

De symbolische orde van de liturgie wordt beheerst door een dominant betekenissysteem, dat van Bijbel, de verhalen van de Bijbel en/of de kerk. Met andere woorden, de symbooltaal van de Bijbel en van de kerk is de voornaamste betekenisgever. Door deze specifieke en dominante betekenisgever ontstaat er een analogie of gelijkenis tussen cultus en cultuur, dat wil zeggen een gelijkheid en een ongelijkheid. Om nog eens het voorbeeld van het licht te nemen: zowel in de cultuur als in de liturgie zal het licht van een kaars/een fakkel tegelijk een symbool van hoop en van bezwering zijn. De paaskaars verdrijft de macht van de nacht en doet uitzien naar de morgen. Maar de paaskaars wijst ook - en die betekenis zal de cultuur zo niet herkennen - naar de vuurkolom die aan Israël voorging door de woestijn en naar de verrezen en ten hemel gevaren Heer.

In de liturgie blijft altijd het primaat van het schriftuurlijke betekenissysteem gelden, hoe problematisch dat inzicht in onze cultuur ook is geworden (zie hieronder). Dat betekent dat de liturgie nadrukkelijk ook contracultureel kan zijn. Toch is goede liturgie ook dan zelf weer opnieuw "cultuur"! Door cultuur en rituelen en dus ook door liturgie worden bepaalde waarden overgedragen en worden mensen ook gemanipuleerd. Het behoort tot de taak van de ritual studies om de relatie tussen rite en context en tussen rite en cultuur zichtbaar te maken. De liturgiek zal daarbij steeds het bijbelse symboolsysteem als ijkpunt nemen. Welke waarden en waardenconflicten impliceren bepaalde riten? Hoe maken riten gebruik van macht? Kortom, in een ritueelkritische benadering 
worden de politieke, ethische en esthetische implicaties van een rituele orde bloot gelegd. Het doel van deze ritueelkritische benadering is een verbetering van de rituele praxis door een recontextualisatie (Grimes $1990,16)$. Het is evident dat de rituelen van Nazi-Duitsland de nationaal-socialistische ideologie versterkten. Dat daarbij ook het esthetische in dienst van het demonische kan worden genomen, blijkt uit de films van Leni Riefenstahl. Van feministische zijde wordt, zoals gezegd, steeds gewezen op een rituele taal die, soms subtiel, de masculiene predominantie bevestigt en versterkt. Omgekeerd hebben vieringen voor en door bijvoorbeeld vrouwen of homo's, juist een emancipatoir karakter. Hetzelfde geldt van bijvoorbeeld de Latijns-Amerikaanse Missa Salsa, die het ritueel gestalte geeft in het idioom van een niet-opgelegde cultuur. Onderzoek naar de verhouding tussen ritualiteit, cultuur of cultus en context heeft dus een kritische functie. Daarbij geldt, aldus Grimes, dat riten culturen moeten kritiseren en dat zij zelf gekritiseerd moeten worden door culturen (Grimes 1990, 57). Niet alleen maken rituelen deel uit van de cultuur, maar er bestaat ook een wisselwerking tussen beide en volgens Grimes moeten zij kritisch op elkaar betrokken blijven. Dat impliceert dat voor een kritische benadering zowel kennis van de culturele code als van de liturgische of rituele code noodzakelijk is.

\section{TWEEDE TENDENS: INTERFERENTIE VAN VERSCHIL- LENDE BETEKENISSYSTEMEN}

\subsection{De mens als spin in een web}

De westerse cultuur verandert momenteel snel van een meer hiërarchische naar een meer als netwerk georganiseerde cultuur. "Netwerken" is een sleutelbegrip in het postmoderne bewustzijn. Ieder mens vormt zich een uniek en eigen netwerk van relaties en betekenissen. Minder maken we deel uit van een vastliggende sociale structuur, met de familie en de dorps- of stadgemeenschap met hun vaste sociale gelaagdheden en ook de arbeidsomgeving met haar duidelijke hiërarchische structuren, waarin mensen hun vanzelfsprekende plek hebben. Veelmeer treedt er een nivellering op (die niet uitsluit dat bijvoorbeeld op de werkvloer de één grotere beslissingsbevoegdheden heeft dan de ander en ook niet dat er sociale verschillen blijven bestaan in samenlevingen) en staan we in netwerken die we zelf creëren. Individualisme speelt hierin een belangrijke rol.

Deze netwerkcultuur speelt ook een rol in onze kennisverwerving. In toenemende mate wordt kennis vergaard op het wereldwijde web van het internet. Deze kennis is fundamenteel anders geordend dan kennis uit boeken of artikelen. Deze kennis op schrift is lineair en hiërarchisch geordend. Een boek heeft een inhoudsopgave en de bestudering ervan levert aan een hoop informatie op over de kennis die het boek wil overdragen. Kennis via het internet wordt intuïtief en associatief verworven, 
niet via een geordend systeem. Ik klik naar een volgend scherm op grond van een beslissing die niet gebaseerd is op een geordend overzicht van informatie. Overzicht ontbreekt principieel. Ik ben op het internet de individuele speler die mij een web weef van kennis èn van kennissen: ook relaties komen in toenemende mate via het internet tot stand. Ook in deze menselijke relaties treedt een hiërarchie op de achtergrond: op het world wide web is iedereen gelijk (Gabriel 1997). Kortom, kennis en kennissen maken deel uit van een netwerk, een web, waarbij ieder als een spin zijn eigen web weeft.

Deze wijze van kennisverwerving gaat gelijk op met een interferentie van verschillende betekenissystemen. Er is niet meer één vanzelfsprekend dominant betekenissysteem, bijvoorbeeld "kerk" of "Bijbel" of "socialisme". Kerk, kerkdienst, kunst, museum, yoga, meditatie, fitness, vrije tijd, werk, collega's, vrienden of familie zijn inwisselbaar en worden met groot gemak op een gelijk niveau aan elkaar geregen. Ik herinner nog eens aan het voorbeeld van de uitvaartdienst voor Prinses Diana.

Daarmee is het christelijke symboolhandelen, en dus de liturgie, dat immers één dominante betekenisgever veronderstelt, geproblematiseerd. De christelijke liturgie heeft haar bijzondere plek in de samenleving verloren. Eredienst is één van de betekenissystemen waaraan men deelneemt, één van de symbolische orden waaraan men participeert. Maar de betekenissen die participanten aan de christelijke liturgie genereren, worden door ieder individu (of ook wel groepsgewijs) geintegreerd in een sterk individueel bepaald web van betekenissen. Er worden door deelnemers aan rituelen geen geïntendeerde betekenissen gereproduceerd, maar er worden nieuwe betekenissen geproduceerd.

\subsection{Individu, individualisme en individualiteit}

We moeten hier nog een enkel woord wijden aan het individualisme dat in deze netwerkcultuur fundamenteel is. Ik beschouw het artikel "Ich ist ein Anderer" van Henning Luther wat dit betreft als richtinggevend (Luther 1992). Drie punten uit het rijke verhaal licht ik eruit.

In de moderniteit, zo zegt hij ten eerste, was het menselijk subject een centraal begrip in het denken. Na de moderniteit is daar kritiek op gekomen. De kritiek van postmoderne denkers op het subjectbegrip is gericht tegen de "entindividualisierende Universalisierung" (de ontindividualiserende universalisering) (Luther 1992:67). Subject was een verzamelbegrip, waarbij het individu in een collectief werd onderbracht. In een netwerkcultuur gaat het niet meer om de mens als handelend subject in het algemeen, en dus om jedermann (iedereen), maar om jemand (iemand) (Luther 1992:64v.). In de postmoderniteit heeft de subjectiviteit zich ontwikkeld tot particulariteit.

Theologisch legt Luther vervolgens een verbinding met Schleiermacher, zonder daar overigens diep op in te gaan. We maken daarom een 
kort excurs naar Schleiermacher. Voor Schleiermacher is individualiteit een kernbegrip is waar we niet achter terug kunnen (Barnard 2000:14v. en 19; Barnard 2001d). In de liturgie of in de beschouwing van een kunstwerk wordt het gevoel geprikkeld. Deze prikkeling van het gevoel bestaat niet zonder de concrete manifestatie, zonder de expressie of "Darstellung" ervan: ze uit zich onmiddellijk in de productie van betekenissen of symbolen. De beschouwer van een kunstwerk of het gemeentelid dat participeert in de liturgie is actief aanwezig, zó dat zijn bewustzijn wordt gestimuleerd en hij dus steeds nieuwe betekenissen en symbolen produceert. De individuele hoorder of kijker is in een permanent proces van zingeving geïnvolveerd en vormt een individueel netwerk van betekenissen. Daarmee zijn de cultuur en ook de liturgie gedynamiseerd; zij zijn immers geen statische entiteiten met vastliggende betekenissen, maar worden permanent individueel of groepsgewijze toegeëigend, dat wil zeggen gedifferentieerd in nieuwe betekenissen. Daarin beschouw ik Schleiermachers denken als nauw verwant aan het postmoderne. Schleiermacher verliest in zijn denken vanuit het individu de gemeenschappelijkheid niet uit het oog, maar gemeenschappelijkheid betekent de vereniging van individuen (er geldt dus niet: het individu wordt uit gemeenschap geboren). Voor Schleiermacher is wat hij noemt "die Zirkulation des religiösen Interesses" een belangrijke dimensie van de liturgie. Ik vertaal dat als: het individuele wordt in roulatie gebracht, of: de verschillende individuele betekenisnetwerken worden met elkaar in verbinding gebracht. Zo ontstaat een symbolische orde, die vervolgens weer de context is van de individuele expressie (Barnard 2000; Barnard 2001d).

Ten derde: Luther wijst op Levinas en zijn humanisme van de andere mens. Deze ander is wezenlijk vreemd en breekt binnen in mijn individualiteit, en ontwortelt en ontheemd mij. Hier ontmoeten we de religieuze mens. De religieuze mens is de ontheemde, die zich verhoudt tot het hem vreemde: hij wordt niet gerepresenteerd in Odysseus die terugkeert naar Ithaka, maar in Abraham die uittrekt uit Ur der Chaldeeën (Luther 1992:81v.). Dat brengt ons weer terug bij Schleiermacher: praktische theologie begint bij het geraakt zijn (bij het "Gefühl schlechthinniger Abhängigkeit").

Ik maak een kanttekening hierbij. Als we een tendens tot individualisering waarnemen, wil dat niet zeggen dat er geen enkele collectiviteit meer is. Betekenissen worden ook groepsgewijs toegeëigend. Men kan denken aan heel verschillende jeugdculturen die in Europa bestaan, die gemeenschappelijke codes en riten hebben. Evenzo zijn binnen de protestantse kerken (in Nederland en in Zuid Afrika, maar ook elders) "families" te onderscheiden met gemeenschappelijke rituelen en symbolen, zo goed als de gehele wereldkerk zogenoemde transculturele rituelen en symbolen kent (bijvoorbeeld: Schrift, avondmaal en doop). 
Bij het denken over de liturgie als symbolische orde, kunnen de deelnemers nauwelijks meer als collectief worden gedacht, maar dient gerekend te worden met een sterk individuele toe-eigening. Het meest evident is dit in begrafenis- en huwelijksliturgieën, die sterk het stempel dragen van de gestorvene of diens nabestaanden, en van het bruidspaar. Ook de rituele mogelijkheden op het internet wijzen in deze richting. De talloze virtuele begraafplaatsen op het world wide web, met hun gedachtenisplekken, foto's en andere memorabilia van gestorvenen, de mogelijkheden om teksten achter te laten, virtueel bloemen te leggen en kaarsen te ontsteken, zijn wat dit betreft significant (zie bijvoorbeeld "World Wide Cemetery" of "memorialplace.nl").

Daarnaast moet ermee gerekend worden dat de tendens waarin verschillende betekenissystemen interfereren, geen halt houdt bij de deur van de kerk. De uitvaartdienst voor Diana is hierin exemplarisch.

5 DERDE TENDENS: HET OORSPRONKELIJK ENE DOMEIN VAN DE VERBEELDING, DAT EVOLUEERDE TOT DE TWEE DOMEINEN VAN KUNST EN LITURGIE, WORDT WEER HERSTELD

\subsection{Van der Leeuw en de "eenheid des levens"}

In 1932 en bij herhaling in 1948 bepleitte de bekende Nederlandse hoogleraar Gerardus van der Leeuw (1890-1950) - hij was onder meer de oprichter van de Liturgische Kring en auteur van boeken over liturgie en sacramentstheologie (Van der Leeuw 1946; 1949) - tegenover de gedifferentieerde en gefragmenteerde cultuur die hij om zich heen zag, een "eenheid des levens". Van der Leeuw constateert dat de "eenheid des levens" verloren is gegaan en dat wetenschap, kunst en religie zijn gescheiden; ze bestaan "voor een eigen kring, van een eigen kring. [...] Wij dansen - en dan bidden we niet; of we bidden en dan dansen we niet. Wij werken en we bidden noch dansen" (Van der Leeuw 1948b:36). Hij ziet het als zijn taak de eenheid in de cultuur zoveel mogelijk te herstellen (Hubbeling 1986:10). Deze eenheid is een concept dat Van der Leeuw tegenover het analytische denken van het Verlichtingsrationalisme stelt. Het heft het - voor de wetenschap essentiële - onderscheid tussen subject en object op en oriënteert zich op een intuïtieve kennis (Van der Leeuw 1948a:13; Hofstee 1991:132). In de optimistische jaren kort na de wereldoorlog neemt hij verheugd een hernieuwd verlangen naar eenheid waar (Van der Leeuw 1948b:461). Daarbij waarschuwt hij voor een anticipatie op wat alleen eschatologisch bestaat: er lopen wegen tussen de verschillende levensdomeinen, maar ook grenzen. Die grenzen zullen pas in het eschaton, dus in Gods genade, zijn opgeheven. Een soortgelijk pleidooi als van Van der Leeuw was bijna een eeuw eerder in 
Nederland al gehouden door de theoloog, estheticus en kunsthistoricus Allard Pierson (1831-1896) (Pierson 1904 (1865):15v.).

Verrassend is nu, dat in de netwerkcultuur waarin wij in het begin van de $21^{\mathrm{e}}$ eeuw leven, een dergelijke eenheid weer onverwacht actualiteit heeft gekregen. Daarbij moet dan wel onmiddellijk de kanttekening worden gemaakt, dat het individualisme die eenheid ook tegelijkertijd meer bedreigt dan Van der Leeuw ooit voor mogelijk had gehouden. Verschillende betekenissystemen, verbonden met de verschillende domeinen van het leven, interfereren. De in het tweede voorbeeld beschreven museumdienst is exemplarisch voor het samenbrengen van de domeinen van liturgie en kunst, die naar de overtuiging van Van der Leeuw oorspronkelijk één waren en die religieuze mensen telkens zien samenvloeien (Van der Leeuw 1948b:471).

\subsection{Het ene domein van de verbeelding}

Zoals we zagen, gaat het zowel in de liturgie als ook in de kunst om een symbolische orde. We kunnen dat ook anders zeggen, met citaten van $\mathrm{K}$ H Miskotte en van G K Chesterton. Miskotte zei - het is het motto van De weg van de liturgie (Oskamp en Schuman 1998): “... aan haar feesten kent men de christelijke kerk ... aan haar lied meer dan aan haar dogma ..." Chesterton zei - het wordt instemmend aangehaald door Van der Leeuw (Van der Leeuw 1048b): "Art is the signature of man". De mens met zijn cultuur en zijn cultus kent men aan zijn symbolisch vermogen, aan zijn verbeelding.

In Nederlandse kerken wordt veel geëxperimenteerd met kunst in kerkdiensten (Overbosch 1998; Steensma 1987 en 1993; Thijs 1990). In de liturgiewetenschap in Nederland zien we per consequentie een tendens om kunst en liturgie in hun samenhang te onderzoeken, juist vanuit het ritueel-symbolisch perspectief (Barnard en Post 2001). Kennelijk is de tijd er rijp voor om domeinen die oorspronkelijk één waren, maar die evolueerden tot de twee domeinen van kunst en liturgie, weer in hun eenheid te herstellen.

De kerk heeft daarmee wel een probleem te overwinnen. In de Middeleeuwen en tot ver in de Renaissance zijn de kerk of aan de kerk verbonden personen of instanties de nagenoeg uitsluitende opdrachtgevers aan kunstenaars. De kerk beheerste de kunst, of, positiever gezegd, de kunstenaar ontleende zijn inspiratie aan de opdracht die hem door de kerk werd verstrekt. Aan het einde van de Middeleeuwen begint een proces waarin de kunstenaar zich van zijn opdrachtgever en van de vaste norm en code van de kerk en het verhaal dat de kerk vertelt, begint te bevrijden. De eerste kunstenaar bij wie we dat, terugkijkend, kunnen waarnemen is Giotto di Bondone. Zijn fresco's zijn onder andere te zien in de Arena- of Scrovegnikapel in Padua (It.) en in de Bovenkerk van de 
Basilica di San Francesco in Assisi (ook in It.), waar hij het leven van Franciscus schilderde. Hij is de eerste die kleuren subjectief begint toe te passen, dus zoals hij ze mooi vindt. De psychologie van de kunstenaar wordt een factor van belang. Opmerkelijk dat hij een levensverhaal schildert in een kerk: de biografie krijgt theologisch gewicht!

In onze tijd put de kunstenaar alleen nog maar uit zichzelf: hij heeft zich bevrijd van de opdrachtgever die zich met de inhoud van het kunstwerk bemoeit en is autonoom geworden. De kerk heeft aan deze emancipatie van de kunstenaar en de kunst meegewerkt door de kunst uit de kerk te verwijderen. Ook het moment waarop dat gebeurde is vrij precies aan te wijzen: rond 1800 wordt Caspar David Friedrich's altaarstuk, het "Tetschener Altar" of "Das Kreuz im Gebirge" geweigerd als altaarstuk en in een museum opgehangen (nu hangt het in Dresden). Daarmee kreeg het museum een religieus geladen werk aan de muur. Uit onderzoek naar de gang van zaken rond deze ballingschap blijkt, dat vooral het feit dat de oude iconografische codes niet meer opgaan voor het doek, tot zijn ballingschap heeft geleid: de voorstelling en de zinnelijke tekendrager worden niet langer in een vastliggende code meer samengehouden (Mädler 1997). In de moderne kunst wijst een duif niet vanzelfsprekend op de Heilige Geest, een slang niet allicht op het kwade, etcetera. Op het doek van Friedrich zien we een rotsige berg, die met dennen is begroeid en waarop een crucifix staat. Brede lichtbanen doorsnijden de roodbewolkte lucht. Dit is geen voorstelling van de kruisiging, van Golgotha, maar van een bergkruis of gedachteniskruis, dat mogelijk wijst op een visioen dat iemand er had van de kruisiging. Het herinnert met andere woorden aan een geloofservaring, die weer nieuwe en niet te fixeren geloofservaringen op gang kan brengen. De betekenis van het schilderij ligt niet vast en precies dat was reden om het doek voor de kerk te weigeren en in het museum in ballingschap te laten gaan. Is het toevallig dat musea uit de $19^{\mathrm{e}}$ eeuw de allure van een kathedraal hebben? Men kan denken aan het Rijksmuseum in Amsterdam, dat door de bekende architect P. Cuypers werd gebouwd, die ook vele (rooms-katholieke) kerken ontwierp. Met een beetje overdrijving kan men zeggen dat de kerken de musea van de religieuze architectuur werden en de musea de sacrale ruimten van de kunst. In de beschreven dienst in het Rotterdamse museum Boymans wordt deze contextwisseling weer omgedraaid.

Het herstel van de eenheid van de domeinen van de verbeelding is overigens al veel langer aan de gang. Ik noem een paar willekeurige voorbeelden. In het noordoosten van Frankrijk ligt de stad Metz. Daar kan men het prachtige romaans-gotische kerkje St. Maximin zien. Aan het begin van de vorige eeuw ontwierp Jean Cocteau, tijdgenoot van Picasso, moderne abstracte ramen voor het gebouw. Florale en bestiale motieven zijn in de plaats gekomen van een geijkt christelijke iconografie. Niet al te ver daar vanaf ligt Ronchamp, waar Le Corbusier kort na 
de Tweede Wereldoorlog zijn prachtige Notre Dame du Haut bouwde. De liturgische ontwikkelingen in de Nederlandse kerken tenderen al in de jaren zestig van de vorige eeuw in deze richting van een herstel van eenheid tussen kunst en geloof. Architecten, dichters en componisten kregen - via de Van der Leeuw-stichting: Omtmoetingscentrum van kerk en kunst en later ook van de kerken zelf - opdrachten voor het dichten en toonzetten van liederen en teksten voor de liturgie. Ze hebben niet alleen geleid tot het Liedboek voor de Kerken dat een hoge artistieke en theologische kwaliteit heeft, maar ook tot een kerk als de Thomaskerk in Amsterdam-zuid van de architect Karel Sijmons en "bouwpastor" dominee W G Overbosch, maar ook tot een compositie als Psalm 122 van de jazzmusicus Willem Breuker. De geleidelijke overgang van een meer lerende naar een meer vierende liturgie in de protestantse kerken, staat gelijk aan het betreden van een domein van een vanzelfsprekende aandacht voor het symbolische. De experimentele museumdienst is zo bezien slechts een uiterste consequentie uit een waargenomen ontwikkeling.

\subsection{Autonomie en heteronomie}

Toch is er een verschil tussen een herstel van de eenheid van de verschillende domeinen van de verbeelding in een experiment als in Boymans en de kunstwerken die in opdracht van de kerk of daarmee verbonden instanties werden vervaardigd. De kunst is in principe autonoom en autonomie verdraagt zich lastig met het christelijk geloof, dat zich immers juist door een Stem die niet de eigen stem is, laat gezeggen. Anders gezegd, het geloof is heteronoom. De kunstopdracht en zeker de kunstopdracht vanwege de kerk is daarom een inbreuk op de autonomie en allerminst vanzelfsprekend (Barnard 1997; Barnard en Van der Werff 1997). En precies dàt is het probleem dat de kerk heeft te overwinnen. Daarbij is het overigens niet uitgesloten - zie het experiment van de museumdienst - dat kunstenaar en gemeente min of meer toevallig samenstemmen (De Wal 1999). Gemeente en gemenebest, kerk en wereld, cultus en cultuur blijken steeds weer gelijkheid èn ongelijkheid te vertonen: zij zijn elkaars analogie en staan in een dynamische relatie tot elkaar (Barnard 1996). Het symbool is de plek waar het Heilige tegelijk aanwezig en afwezig is.

\section{VIERDE TENDENS: EEN (SOMS RADICALE) RECONTEX- TUALISERING VAN DE LITURGIE}

\subsection{Een kritische liturgiewetenschap en recontextualisering}

Liturgiewetenschap heeft een kritische functie, zo zeiden we, door de continuilteit en discontinuilteit tussen een liturgie en een cultuur bloot te leggen en te laten zien hoe mensen zich een liturgie (en een cultuur) toe- 
eigenen. Anders gezegd, liturgiek wijst steeds op het dynamisch karakter van liturgische rituelen. Deze dynamiek staat op gespannen voet met de vermeende onveranderlijkheid van de rituele traditie. Daarom gaan we hieronder eerst in op wat traditie is.

Riten en symbolen zijn met traditie te verbonden, met overlevering. Doop en avondmaal worden al twee millennia lang door christenen gevierd. Maar steeds zal de liturgiewetenschap weer duidelijk maken dat wat wordt gepresenteerd als "de" traditie, in feite een traditie is: de beide sacramenten worden op heel verschillende manieren gevierd in verschillende tijden en op verschillende plaatsen. De tendens van het ritueel om zich als eerbiedwaardig en onveranderlijk te presenteren, is verbonden met het feit dat riten en mythen zich op enigerlei wijze met het verleden verstaan. Maar deze tendens staat, zoals gezegd, op gespannen voet met de contextuele bepaaldheid van ieder ritueel. Sinds in de zestiende eeuw kritisch historisch onderzoek op gang kwam, ook naar de liturgie van de kerk, wordt steeds duidelijker dat "de" traditie altijd al meerdere tradities bleek te omvatten. Rituelen zijn in feite steeds contextueel bepaald en aan verandering onderhevig (Hobsbawm en Ranger 1999).

Wie deelneemt aan het ritueel van de kerk is de eerste niet en ook de laatste niet. In de leer van de Rooms-katholieke kerk heeft traditie (bij voorkeur geschreven met een hoofdletter) een normatieve betekenis. Toch is het maar één traditie die als normatief wordt beschouwd onder vele andere. In protestantse kerken is dat formeel anders, maar dat wil niet zeggen dat er geen groot gezag van tradities uitgaat. De klassieke doop- en avondmaalsformulieren, zoals die in de zestiende eeuw door de Synoden van Dordrecht zijn vastgelegd, zijn in bepaalde kringen bijna sacrosanct. Toch zien we dat ook die onder invloed van de context veranderen.

Deze verandering of recontextualisering van de liturgie is opgekomen uit het inzicht dat voor (bepaalde) participanten aan de eredienst waarin deze formulieren worden gelezen, de taal ervan niet meer verstaanbaar was. Anders gezegd, de toe-eigening was problematisch geworden. Een commissie van de Gereformeerde Bond in de Nederlandse Hervormde Kerk maakte daarom een "hertaling" van de zogenaamd Klassieke liturgische formulieren. We zien dat deze hertaling toch meer is dan een vernieuwing van de taal: de bundel formulieren is aangepast aan de tijd en weerspiegelt dus de dynamiek van de cultus: als bijlage is bij de "hertaalde" formulieren van Dordrecht (1574 en 1578) een orde voor de openbare belijdenis opgenomen, die niet uit de zestiende eeuw stamt, maar is overgenomen uit het Dienstboek in ontwerp van 1955. Ook is de zogenaamde "zondecatalogus" in het avondmaalsformulier aangepast aan de moderne tijd. Een enkel voorbeeld: in het klassieke formulier worden "alle tovenaars en waarzeggers, die vee of mensen, mitsgaders andere dingen zegenen en die aan zulke zegeningen geloof 
schenken" gemaand zich van het avondmaal te onthouden. In de hertaling geldt het vermaan allen "die zich bezig houden met occulte praktijken of daaraan geloof hechten" (Klassieke Liturgische Formulieren 2000:26). De polemische spits is verplaatst van de Romana naar de religiositeit van de nieuwe tijd. Nog opmerkelijker zijn de ingrepen in het huwelijksformulier: in de klassieke versie zijn de verschillen tussen man en vrouw sterk aangezet en is de mannelijke dominantie over de vrouw evident; in de hertaling wordt vooral de gelijkheid tussen beide huwelijkspartners geaccentueerd.

Deze hertaling is een aanpassing van rituele teksten uit het verleden; we zien ook, omgekeerd, hoe in de kerken op een eigen wijze wordt teruggegrepen op wat geldt als de traditie. Deze omgang met het verleden is doorgaans selectief. Door zaken uit het verleden selectief in het heden toe te passen vindt ook een radicale contextwisseling plaats: elementen uit de liturgie van de vroege of middeleeuwse kerk worden in het heden opgenomen. Een voorbeeld in de protestantse kerken in Nederland is het getijdengebed, bijvoorbeeld de vesper, dat op vele plaatsen en meestal incidenteel wordt gevierd (Dienstboek 1998:962-986). Diensten die voorheen door een vaste groep monniken en monialen in de kloosters met ijzeren regelmaat werden gebeden, worden nu incidenteel door een wisselende groep gevierd. Zo is er zowel sprake van continuïteit als van discontinuitteit met het verleden (vergelijk Lukken 1997).

\subsection{Bij wijze van conclusie: de noodzaak van een recontextualise- ring van de liturgie en de taak van de liturgiewetenschap}

We begonnen dit artikel met twee voorbeelden en distilleerden daar vier tendensen uit in de dynamiek van cultus en cultuur. Het eerste voorbeeld, van Prinses Diana als postmoderne heilige, wees niet alleen op een spontane opbloei aan ritualiteit, maar ook op een spontane recontextualisering van het kerkelijke (begrafenis-)ritueel, die een interferentie van verschillende betekenissystemen impliceerde. Het tweede voorbeeld, een kerkdienst in museum Boymans, was niet spontaan van karakter, maar experimenteel. Het wees op de tendens de domeinen van liturgie en kunst beide onder de noemer van de verbeelding te brengen. Beide voorbeelden laten een geslaagde recontextualisering zien. Juist het succes van deze spontane (Diana) en georganiseerde (Boymans) recontextualisering, maakt de noodzaak ervan duidelijk.

Het kerkelijk ritueel heeft de neiging zich in zichzelf terug te trekken, zoals de kerk, althans in Nederland, tendeert naar een verkerkelijking. De liturgiewetenschap kan deze tendens heel gemakkelijk bevestigen door zich te richten op het binnenkerkelijke ritueel. Als kritische (kerkelijke) discipline heeft zij mijns inziens de taak de culturele en antropologische verankering van de kerkelijke rituelen en symbolen te onderzoeken, en dus de dynamiek van cultus en cultuur. Dat impliceert 
niet, dat zij dus iedere culturele en antropologische tendens volgt: liturgie kan contracultureel en wie weet contra-antropologisch zijn en moeten zijn. Het evangelie gaat immers soms tegen de cultuur en tegen de mens in. Maar die contraculturele houding zal dan tenminste wel moeten worden benoemd en gerealiseerd als contracultureel. Telkens zal de wetenschap zich daarbij in de postmoderniteit moeten beseffen, dat "cultuur" een pluralistisch begrip is, omdat het als eventuele eenheid telkens wordt opengebroken door een sterk individueel bepaalde of groepsgewijze toe-eigening. Positief is dat te duiden als een actief hermeneutisch proces van betekenisgeving, waarin mensen in het symboolhandelen van de kerk "doorgeefluiken van de Godontmoeting" vinden.

\section{Literatuurverwijzingen}

Augustus-Kersten, A 2000. Liturgie in geseculariseerde context. Liturgie in het hol van de leeuw? Eredienstvaardig 16/3 (2000) 84-88.

Bank, J en Van Buuren, M 2000. 1900: Hoogtij van burgerlijke cultuur, Den Haag: Sdu Uitgevers.

Barnard, M 1996. Forma Lucis. Een gereformeerde theologie van de kleur. Nederlands Theologisch Tijdschrift 50/2 (1996) 135-151.

Barnard, M 1997. Kunst die niet niets voorstelt. De kunstopdracht als methode voor het gesprek tussen 'kerk' en kunst, in Deurloo, Karel en Hoekema, Alle (red.), Van masker tot aangezicht. Opstellen over bijbelse theologische en kerkelijke confrontaties. Baarn: Ten Have, 95-109.

Barnard, M 2000. Liturgiek als wetenschap van christelijke riten en symbolen. Oratie Universiteit van Amsterdam. Amsterdam: Vossiuspers AUP.

Barnard, M 2001a. Dynamiek van cultus en cultuur, in Barnard, Marcel en Post, Paul, Ritueel bestek. Antropologische kernwoorden van de liturgie, Zoetermeer: Meinema, 47-55.

Barnard, M 2001b. Een kerkdienst in een museum, in Barnard, Marcel en Post, Paul (red.), Ritueel bestek: Antropologische kernwoorden van de liturgie. Zoetermeer: Meinema, 56-62.

Barnard, M 2001c. Zon, licht, vuur, kleur et cetera, in Barnard, Marcel en Post, Paul (red.), Ritueel bestek: Antropologische kernwoorden van de liturgie. Zoetermeer: Meinema, 241-258.

Barnard, M 2001d. 'Secular Festival and Christian Feast in Schleiermacher's "Practical Theology" and "Aesthetics". A Theoretical Contribution to the Study of Liturgy and Arts', in Post, Paul en Rouwhorst, Gerard en anderen, Christian Feast and Festival. The Dynamics of Western Liturgy and Culture. Liturgia Condenda. Leuven: Peeters (te verschijnen).

Barnard, M en Post, P (red.) 2001. Ritueel bestek: Antropologische kernwoorden van de liturgie. Zoetermeer: Meinema.

Barnard, M en Werff, A (red.) 1997. Kunstopdrachten. Onderbreking, deel 1. Kampen: Kok.

Bell, C 1997. Ritual: Perspectives and Dimensions. New York: Oxford University Press.

Blankesteijn, H 2001. Liturgie op museumbezoek, I, II en III. In de waagschaal 30/3 (2001) $21-23$; 30/4 (2001) 12-14; 30/5 (2001) 17-20. 
De Klerk, B 2002. Liturgie, transformasie en die Afrika Renaissance, in Barnard, Marcel en Schuman, Niek (red.), Nieuwe wegen in de liturgie: De weg van de liturgie - eerste vervolg. Zoetermeer: Meinema (accepted).

Dienstboek 1998. Dienstboek, een proeve. Schrift, Maaltijd, Gebed. Zoetermeer: Boekencentrum.

Fokkema, D en Gijzenhout, F (red.) z.j. (te verschijnen). Rekenschap. Den Haag: Sdu Uitgevers.

Frijhoff, W en Spies, M 1999. 1650: Bevochten eendracht. Den Haag: Sdu Uitgevers.

Gabriel, N 1997. Kulturwissenschaften und neue Medien. Wissensvermittlung im digitalen Zeitalter. Darmstadt: Wissenschaftliche Buchgesellschaft.

Geertz, C 1993 (1973). The Interpretation of Cultures. Londen: Fontana Press (New York: Basic Books).

Grimes, R 1990. Ritual criticism. Case studies in its practice, essays on its theory, Columbia: University of South Carolina Press.

-, 2000. Deeply into the Bone. Re-inventing rites of passage. Berkeley/Los Angeles/Londen: University of California Press.

Grond, A 1998. Het museum is geen tempel. De Bazuin 3 april 1998, 32.

-, 1998. Het museum is geen tempel. De Bazuin 3 april 1998, 32.

Hobsbawm, E en Ranger, T (red.) 1999 (1983). The Invention of Tradition. Cambridge: Cambridge University Press.

Hofstee, W 1991. Gerardus van der Leeuw and the Concept of Primitive Mentality, in Kippenberg, H.G. en Luchesi B. (red.), Religionswissenschaft und Kulturkritik, Marburg: Diagonal Verlag, 127-137.

Houtepen, A 2001. Theologen op zoek naar God. Twintig portretten van katholieke theologen uit de tweede helft van de $20^{\text {ste }}$ eeuw. Zoetermeer: Meinema.

Hubbeling, H.G. 1986. Divine Presence in Ordinary Life: Gerardus van der Leeuw's twofold Method in his Thinking on Art and Religion. Mededelingen der Koninklijke Nederlandse Academie van Wetenschappen, afd. Letterkunde, Nieuwe Reeks, deel 49 - no. 1. Amsterdam, Oxford, New York: North-Holland.

Klassieke liturgische formulieren 2000. Klassieke liturgische formulieren. Voorlopige uitgave. Z.p.: Gereformeerde Bond in de Nederlandse Hervormde Kerk.

Kloek, J en Mijnhardt, W 2001. 1800: Blauwdrukken voor een samenleving. Den Haag: Sdu Uitgevers.

Krog, A 1998/1999. Country of my Skull. Parktown: Random House (Pty) Limited/ Londen: Jonathan Cape.

Lang, B 1998. Heiliges Spiel. Eine Geschichte des christlichen Gottesdienstes. München: Beck (Sacred Games. A history of Christian Worship. New Haven/ Londen 1997: Yale University Press)

Leeuw, G van der 1946. Liturgiek. Nijkerk: Callenbach.

-, 1949. Sacramentstheologie. Nijkerk: Callenbach.

-, 1932. Wegen en grenzen. Studie over de verhouding van religie en kunst. Amsterdam: Paris.

-, 1948a. Inleiding tot de phaenomenologie van den godsdienst. Haarlem: De erven F. Bohn N.V.

-, 1948b. Wegen en grenzen. Amsterdam: Paris. Tweede en [sterk] herziene druk van Van der Leeuw: 1932.

Lukken, G, Liturgiewetenschappelijk onderzoek in culturele context: Methodische verhelderingen en vragen. Jaarboek voor liturgieonderzoek 13 (1997) 135-148. 
-, 1999. Rituelen in overvloed: Een kritische bezinning opde plaats en de gestalte van het christelijke ritueel in onze cultuur. Baarn: Gooi en Sticht.

Luther, H 1992. Religion und Alltag. Bausteine zu einer Praktischen Theologie des Subjekts. Stuttgart: Radius-Verlag.

Mädler, I 1997. Kirche und bildende Kunst der Moderne. Ein an F.D.E. Schleiermacher orientierter Beitrag zur theologischen Urteilsbilding. Beiträge zur historischen Theologie 100. Tübingen: Mohr Siebeck.

Museum Boijmans van Beuningen 1998. Verzachtende omstandigheden. Wandtapijten in het Paleis van Justitie 's Hertogenbosch. Rotterdam: Uitgeverij 010.

Oskamp, P en Schuman, N 1998. De weg van de liturgie. Tradities, achtergronden, praktijk. Zoetermeer: Meinema.

Overbosch, W G 1998. Beelden in de kerk? Ook in Nederland weer een brandende kwestie; essay naar aanleiding van Günther Rombold, Der Streit um das Bild: zum Verständnis von moderner Kunst und Religion, in Zo gezien. Gebundelde opstellen. Zoetermeer: Boekencentrum, 147-168

Pierson, A 1904 (1865). 'Dr. A. Pierson aan zijne laatste gemeente', in Uit de verspreide geschriften. Tweede reeks I. Den Haag: Martinus Nijhoff.

Post, P 1998. Het rituele perspectief, in Harskamp, Anton van (red.), De religieuze ruis in Nederland: Thesen over de versterving en de wedergeboorte van de godsdienst. Zoetermeer: Meinema.

-, 2000a. De moderne heilige: sacrale interferenties. Een terreinverkenning. Jaarboek voor liturgieonderzoek 16 (2000) 135-160.

-, 2000.Het wonder van Dokkum. Verkenningen van populair religies ritueel. Nijmegen 2000.

-, 2001. Ritualiteit als symboolhandelen, in Barnard, Marcel en Post, Paul (red.), Ritueel bestek: Antropologische kernwoorden van de liturgie. Zoetermeer: Meinema, 33-46.

Rappaport, $\mathrm{R}$ 1999. Ritual and Religion in the Making of Humanity. Cambridge Studies in Social and Cultural Anthropology, 110. Cambridge/New York: Cambridge University Press.

Schuyt, K en Taverne, E 2000. 1950: Welvaart in zwart-wit. Den Haag: Sdu Uitgevers.

Stauffer, S A (red.) 1994. Worship and culture in dialogue. Genève: Lutheran World Federation.

-, S A (red.) 1996. Christian worship: Unity in cultural diversity. Genève: Lutheran World Federation.

-, S A 1997. Worship and culture: A select bibliography. Studia Liturgica 27 (1997) 102-128.

-, (red.) 1998. Baptism, rites of passage, and culture. Genève: Lutheran World Federation.

Steensma, R 1987. In de spiegel van het beeld. Kerk en moderne kunst. Baarn: Ten Have.

-, 1993. Mysterie en vergezicht. Over het gebruik van hedendaagse beeldende kunst in de liturgie. Baarn: Gooi en Sticht.

Thijs, B 1990. Geloven uit de kunst? Een pleidooi voor geloofsverbeelding in de gemeente. Den Haag: Meinema.

Vischer, L e.a. (red.) 2002. Christian Worship in Reformed Churches: Past and Present. Grand Rapids: W. Eerdmans. (In voorbereiding).

Vos, C J A en Pieterse, H J C 1997. Hoe lieflik is $u$ woning. Pretoria: Die RGN Uitgewery (Studies in Praktiese Teologie). 
Wal, J de 1999. Kunst zonder kerk. Aspecten van religie in de Nederlandse autonome beeldende kunst tussen 1945 en 1990 met bijzondere aandacht voor de jaren tachtig. Dissertatie Rijkuniversiteit Groningen. Uitgegeven in eigen beheer. 